\title{
WEAR OF MEDIUM CARBON STEEL UNDER FRICTION LOADING WITH VARIOUS CONTACT SURFACE TEMPERATURE
}

Program Magist m.widiyarta@unud.ac.id

I Made Parwata

Tenaga Pengajar (Dosen) Universitas Udaya Fakultas Teknik Program Studi Teknik Mesin/ Program Magister S2 Teknik Mesin md parwata@unud.ac.id

I Putu Lokantara

Tenaga Pengajar (Dosen) Universitas Udaya Fakultas Teknik Program Studi Teknik Mesin lokantara@unud.ac.id

Dwipayana

Mahasiswa S2

Universitas Udaya

Fakultas Teknik

Program Magister S2 Teknik Mesin
The work presented in this paper is to investigate the wear rate and wear mechanism of medium carbon steel with carbon contents of about 0,5 wt.\% under the friction load with various contact surface temperatures. The wear test was performed by using the linear reciprocating ball-on-flat wear test machine. To develop the elevated temperature on the surface of the wear test specimen, the heater assembled into the wear test machine. The surface temperature of the wear specimen was set in the range of $30^{\circ} \mathrm{C}$ up to $250^{\circ} \mathrm{C}$. The test was taken under 5000 cycles of friction loading with a maximum of the normal load of $25 \mathrm{~N}$. The experiment results show that the change in the contact surface temperature in the range of $30{ }^{\circ} \mathrm{C}$ up to $250{ }^{\circ} \mathrm{C}$ causes the wear rate to increase slightly. This is because the elevated temperature at the surface was not high enough to cause the hardness of the material to decrease significantly. The worn surface looks very thin scratches and slightly deformed layers, and the wear mechanism had identified as the oxide wear.

Keywords: Friction Load, Surface Temperature, Medium Carbon Steel, Wear.

\section{PENDAHULUAN}

Dua buah benda yang mengalami kontak dan bergesekan satu dengan yang lainnya dapat mengakibatkan terjadinya kegagalan aus pada kedua benda tersebut. Kegagalan aus merupakan kegagalan permukaan yang sangat progresif, yaitu terlepasnya lapisan material dipermukaan dalam bentuk partikel [1]. Pada material yang ulet seperti baja karbon, kegagalan aus yang terjadi akan diawali dengan proses deformasi plastis. Bila akumulasi deformasi plastis oleh pembebanan yang berulang melampaui nilai kritisnya maka material tersebut akan patah dan terlepas dari permukaan sebagai partikel aus $[1,2]$. Gesekan yang terjadi antara kedua benda dapat menimbulkan terjadinya panas pada permukaan kontak kedua benda tersebut. Suhu di permukaan kontak akan meningkat bila beban dan kecepatan gesekan meningkat [3]. Apabila panas yang terjadi atau suhu dipermukaan relatif cukup tinggi, maka suhu permukaan tersebut dapat meurunkan sifat mekanis material, kekuatan luluh baja karbon secara umum dapat turun mencapai $20 \%$ pada suhu $300^{\circ} \mathrm{C}$ [4] dan mungkin juga dapat mempengaruhi ketahanan aus material tersebut. Jika kekuatan luluh material turun, maka material akan lebih mudah terdeformasi plastis, hal ini tentu akan mempercepat akumulasi deformasi plastis mencapai nilai kritisnya dan berdampak pada kegagalan aus akan lebih cepat terjadi. Uji kekerasan pada material baja karbon pada suhu permukaan sampai $250^{\circ} \mathrm{C}$ telah dilakukan, dan diketahui kenaikan suhu permukaan tersebut tidak dapat menurunkan kekerasan secara signifikan, kondisi ini dipengaruhi oleh terbentuknya lapisan oksida di permukaan [5]. Tingkat keausan dan mekanisme kegagalan aus material yang mengalami beban kontak gelinding luncur dengan mempertimbangkan adanya thermal stresses pada permukaan dengan menggunakan simulasi model komputer. Dari hasil simulasi diperoleh bahwa tegangan panas akibat beban gesek megakibatkan material menjadi lebih lunak dan lebih mudah mengalami deformasi plastis sehingga kegagalan aus menjadi meningkat [6].

Kondisi lain yang dapat diakibatkan oleh munculnya panas di permukaan benda berbahan logam yaitu 
dapat mempercepat terjadinya proses korosi $[7,8]$ dan juga dapat terjadinya proses oksidasi pada permukaan material [9 - 11]. Pada baja karbon, proses oksidasi di permukaan material dapat terjadi meskipun pada suhu yang rendah (kurang dari $26^{\circ} \mathrm{C}$ ) [9]. Oksidasi akan semakin cepat terjadi bila panas permukaan material terekspose pada ruang terbuka dengan kelembaban yang tinggi [10]. Dalam proses kontak antara dua benda berbahan logam, proses oksidasi menjadi sangat penting untuk diperhatikan. Terjadinya oksidasi mengakibatkan terbentuknya lapisan oksida di permukaan. Lapisan oksida dapat berfungsi melindungi material benda mengalami kontak langsung, yaitu menghambat terjadinya kontak logam dengan logam dan dapat mengurangi terjadinya kegagalan aus pada material [11]. Namun demikian, jika lapisan oksida pada permukaan terkelupas akibat beban gesek dan menjadi partikel aus yang keras, maka partikel aus tersebut dapat terperangkap dalam permukaan kontak. Partikel oksida yang terperangkap tersebut dapat menjadi partikel abrasif yang mungkin dapat mengakibatkan terjadinya kegagalan aus abrasif [12]. Bila kondisi ini terjadi, maka keausan yang terjadi pada benda tersebut akan meningkat.

Dalam penelitian ini, tingkat kegagalan aus dan mekanisme aus material baja karbon sedang dengan suhu permukaan sekitar $30^{\circ} \mathrm{C}$ sampai dengan $250{ }^{\circ} \mathrm{C}$ akan diinvestigasi. Uji aus akan dilakukan pada mesin uji aus ball-on-flat dengan beban gesek arah bolak balik (linear reciprocating ball-on-flat sliding wear machine) dengan memperhatikan standard uji aus ASTM G133 [13].

\section{METODE}

Uji aus dilakukan menggunakan mesin uji aus ball-on-flat (linear reciprocating ball-on-flat wear test machine), sebuat heater untuk memanaskan specimen uji dipasang pada mesin uji aus (Gambar 1) [14]. Material uji menggunakan baja karbon sedang dengan kandungan karbon sekitar 0,5 wt.\% C (Gambar 2) [5] dan dibentuk dengan ukuran $20 \times 15 \times 5 \mathrm{~mm}$. Sebelum uji aus dilakukan, permukaan spesimen uji digerinda untuk meratakan permukaan dan selanjutnya dipoles untuk menghaluskan permukaan dengan kekasaran permukaan sekitar $0,1-0,3 \mu \mathrm{m}$. Selanjutnya spesimen dibersihkan dengan washbensin dan dibersihkan kembali dalam ultrasonic bath dengan cairan etanol.

Sebelum uji aus dilakukan, spesimen uji ditimbang terlebih dahulu untuk memperoleh massa awal specimen dengan menggunakan timbangan dengan akurasi $0,1 \mathrm{mg}$. Spesimen selanjutnya diletakkan pada mesin uji aus diatas plat panas, dengan beban diatur sebesar $25 \mathrm{~N}$ melalui bola indentor dengan diameter bola $8 \mathrm{~mm}$ (menggunakan bola dari ball bearing). Panjang langkah pembebanan diatur sepanjang $10 \mathrm{~mm}$ dengan kecepatan putar penggerak $300 \mathrm{rpm}$ atau setara dengan kecepatan sliding sekitar $0,1 \mathrm{~m} / \mathrm{s}$. Suhu pada heater diatur agar mendapatkan suhu yang diinginkan di permukaan specimen uji, yaitu 30, 50, 100, 150, 200 dan $250{ }^{\circ} \mathrm{C}$. Uji aus selanjutnya dilakukan dengan durasi pengujian selama 5000 kali putaran pembebanan yang ekivalen dengan panjang sliding $100 \mathrm{~m}$. Setelahnya, dilakukan pembersihan dengan menggunakan washbensin dan pembersihan dalam bak ultrasonic. Kemudian spesimen uji ditimbang dengan timbangan digital untuk memperoleh massa akhir. Pengamatan metalurgrafi dilakukan dengan foto Scanning Electron microscope (SEM) dan Electron Dispersive X ray Spectroscopy (EDS) untuk mengamati pola permukaan aus sehingga dapat mengetahui mekanisme aus yang terjadi dan komposisi kimia pembentuk permukaan aus.
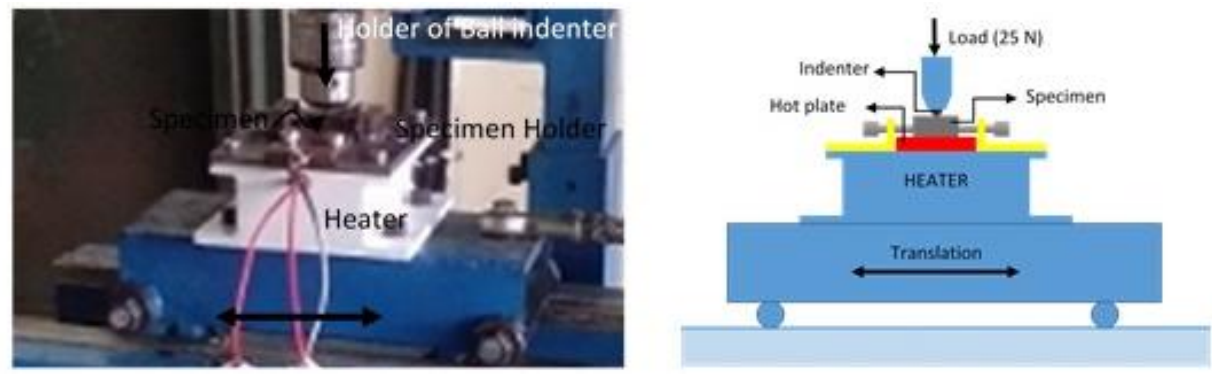

Gambar 1. Diagram mesin uji aus [14] 


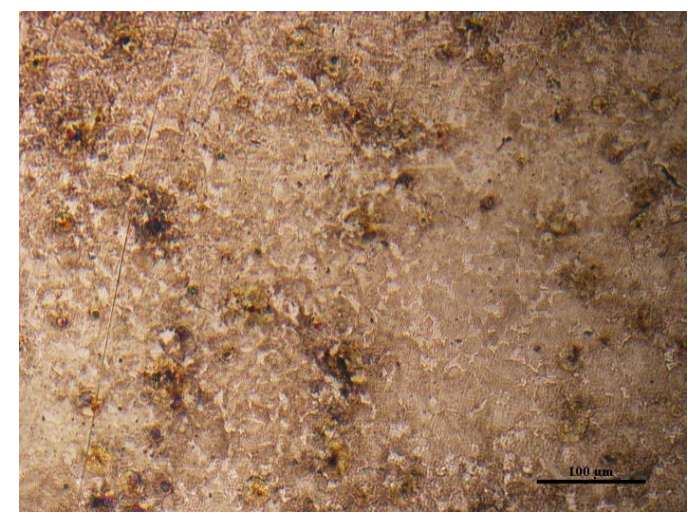

Gambar 2. Photomikro baja karbon sedang

\section{HASIL DAN DISKUSI}

Timbulnya panas di permukaan kontak akibat gesekan dua buah benda dapat mengakibatkan kekuatan material dipermukaan mengalami perubahan. Jika panas yng timbul mencapai suhu yang relative tinggi, kekerasan material dapat turun dan hal ini dapat murunkan ketahan aus material, sehingga mengakibatkan kegagalan aus akan lebih cepat terjadi. Namun demikian, panas yang timbul di permukaan dapat mengakibatkan terjadinya oksidasi dan ini akan membentuk lapisan oksida di seluruh permukaan. Lapisan oksida ini sangat penting untuk diperhatikan karena akan dapat merubah mekanisme kegagalan aus material.

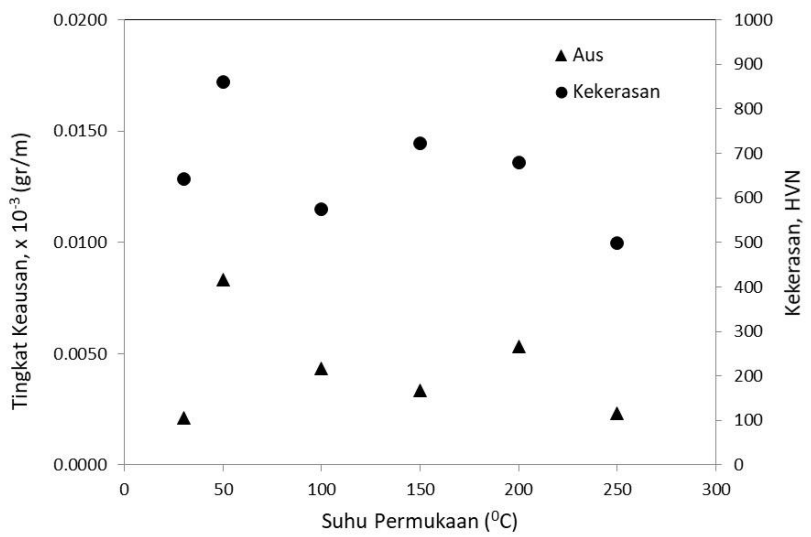

Gambar 3. Korelasi antara suhu permukaan dengan laju keausan dan kekerasan

Gambar 3 menunjukkan kekerasan material (ditunjukkan dalam grafik dengan marka titik, diambil dari pustaka [5]) dan laju keausan baja karbon sedang (ditunjukkan dalam grafik dengan marka segitiga) dengan variasi suhu di permukaan yaitu $30,50,100,150,200$ dan $250{ }^{\circ} \mathrm{C}$. Tingkat keausa sedikit mengalami peningkatan dari sekitar $0,0173 \times 10^{-3} \mathrm{gr} / \mathrm{m}$ menjadi sekitar $0,025 \times 10^{-3} \mathrm{gr} / \mathrm{m}$ dengan naiknya suhu permukaan dari $30{ }^{\circ} \mathrm{C}$ sampai $250{ }^{\circ} \mathrm{C}$. Pada kenaikan suhu permukaan dari $30^{\circ} \mathrm{C}$ sampai dengan $100{ }^{\circ} \mathrm{C}$, tingkat keausan material uji (baja karbon sedang) mengalami peningkatan dari sekitar $0,0173 \times 10^{-3} \mathrm{gr} / \mathrm{m}$ naik menjadi $0,0247 \times 10^{-3} \mathrm{gr} / \mathrm{m}$. Kemudian pada kenaikan suhu permukaan dari $100{ }^{\circ} \mathrm{C}$ menjadi $250{ }^{\circ} \mathrm{C}$, tingkat keausan material berfluktuasi sekitar $0,0225 \times 10^{-3} \mathrm{gr} / \mathrm{m}$ dan $0,0255 \times 10^{-3} \mathrm{gr} / \mathrm{m}$. Dari hasil tingkat keausan terlihat hubungan antara kegagalan aus dengan kekerasan material memiliki hubungan berbanding lurus, hal ini tidak sesuai dengan teori umum hubungan antara kekerasan dengan keausan, dimana material dengan kekerasan lebih tinggi umumnya memiliki kecendrungan ketahanan aus lebih baik, sehingga tingkat keausan umumnya menjadi lebih rendah. Kecuali pada kenaikan suhu permukaan dari suhu $50{ }^{\circ} \mathrm{C}$ ke suhu $100{ }^{\circ} \mathrm{C}$ dan dari suhu $200{ }^{\circ} \mathrm{C}$ ke $250{ }^{\circ} \mathrm{C}$, tingkat keausan material uji sedikit mengalami penurunan. Kondisi tingkat keausan akibat 
variasi suhu permukaan yang tidak stabil mungkin dipengaruhi dengan munculnya lapisan oksida di permukaan (lihat Gambar 5). Lapisan oksida mungkin mengakibatkan kekerasan meningkat dan menurunkan koefisien gesek (gaya geser turun) sehingga mengakibatkan tingkat keausan material menjadi turun. Kondisi lain yang mungkin terjadi, dengan naiknya suhu permukaan sampai $250{ }^{\circ} \mathrm{C}$, yaitu ada kemungkinan kekuatan material uji menjadi turun dan berakibat pada kegagalan aus terjadi lebih cepat sehingga tingkat keausan meningkat. Nilai kegagalan aus akibat naiknya suhu permukaan sampai $250{ }^{\circ} \mathrm{C}$ masih terlihat sangat kecil, hal ini mungkin diakibatkan oleh adanya lapisan oksida yang memberikan perlindukan terhadap terjadinya kontak/gesekan langsung antara material uji dengan material indentor. Gaya geser perlu waktu untuk merusak dan melepaskan lapisan oksida dari permukaan terlebih dahulu sebelum gaya geser dapat mengakibatkan kegagalam pada permukaan material uji sebagai kegagalan aus.
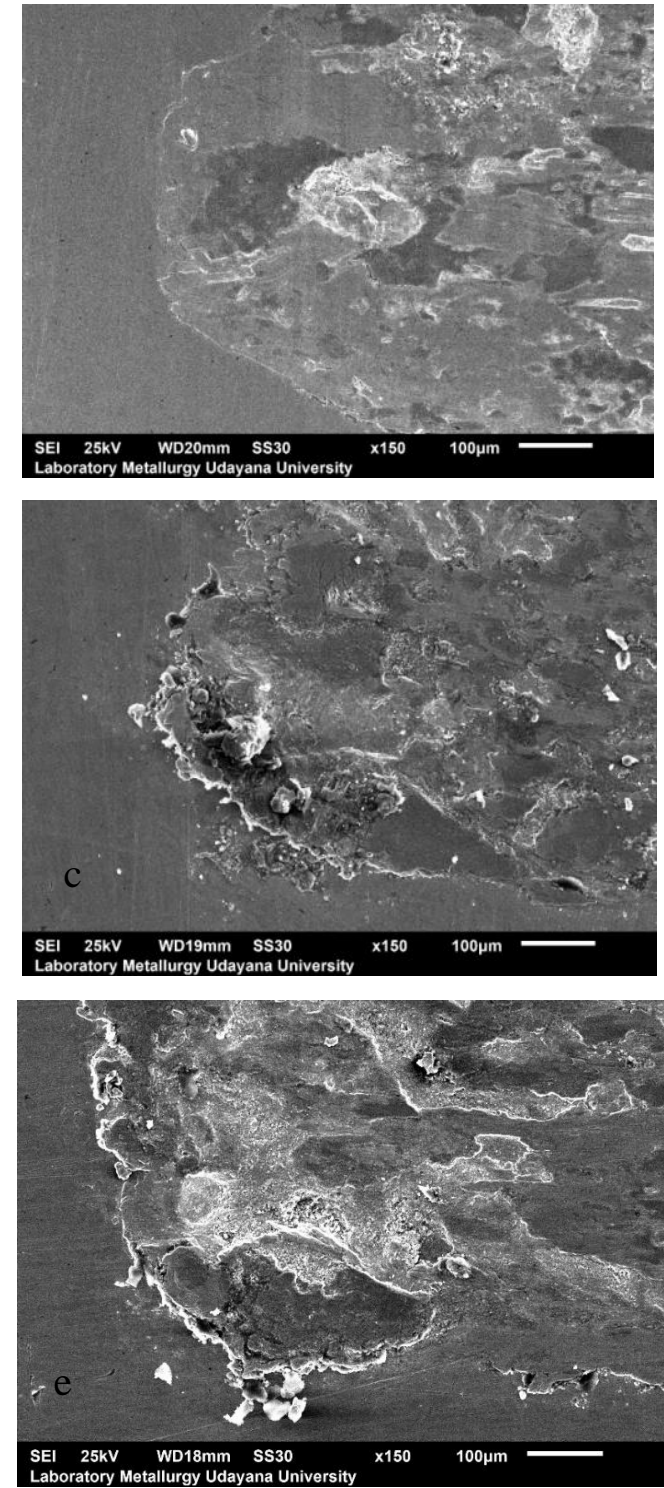
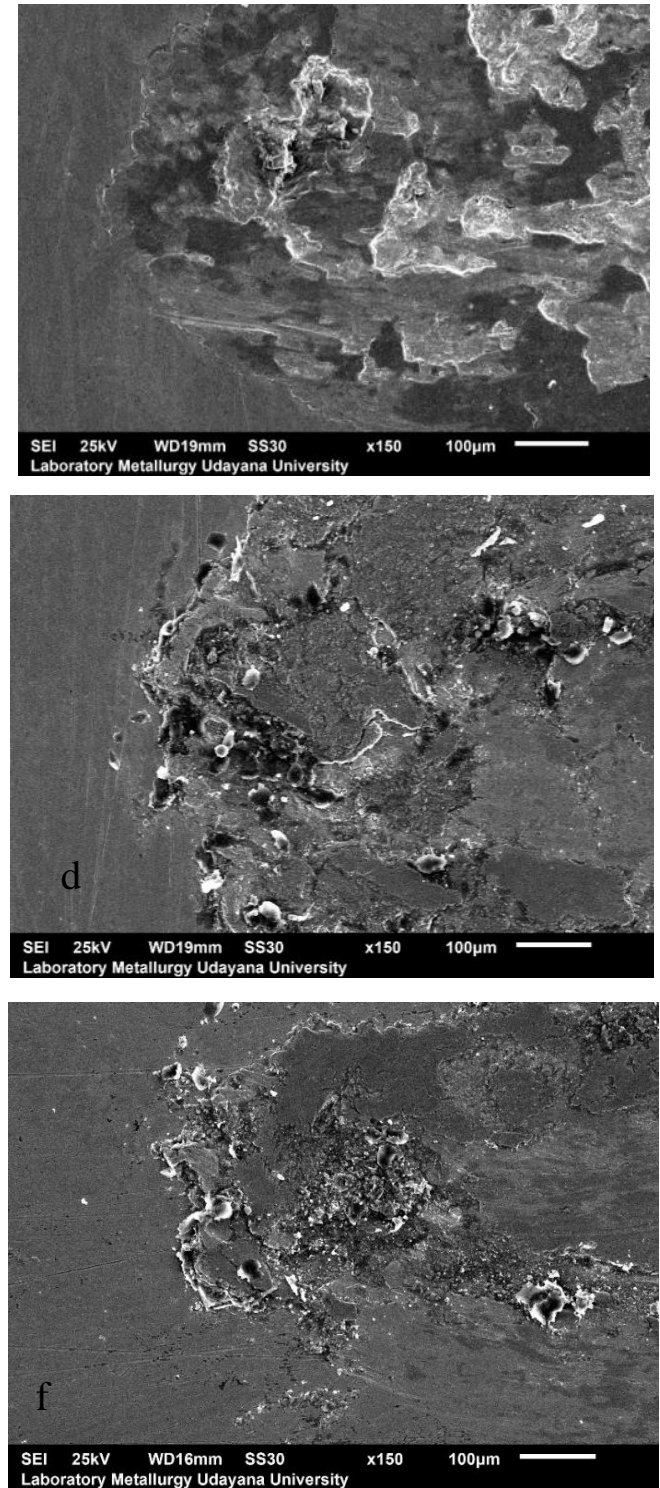

Gambar 4. Photo SEM sisi ujung permukaan aus dengan suhu permukaan (a) $30{ }^{\circ} \mathrm{C}$, (b) $50{ }^{\circ} \mathrm{C}$, (c) $100{ }^{\circ} \mathrm{C}$, (d) $150{ }^{\circ} \mathrm{C}$, (e) $200{ }^{\circ} \mathrm{C}$, dan (f) $250^{\circ} \mathrm{C}$.

Secara umum, tingkat keausan material baja karbon sedang pada suhu permukaan antara $50{ }^{\circ} \mathrm{C}$ samapi dengan $250{ }^{\circ} \mathrm{C}$ lebih besar dibandingkan dengan tingkat keausan pada suhu permukaan $30{ }^{\circ} \mathrm{C}$. Pada awal pembebanan, lapisan oksida memberikan perlindungan pada permukaan material uji terhadap kontak langsung dengan permukaan material indentor. Namun setelah beberapa periode pembebanan, beban geser kemudian dapat merusak lapisan oksida dan melepaskannya sebagai partikel aus. Selanjutnya, pada pembebanan berikutnya, partikel aus dari lapisan oksida tersebut mungkin terperangkap diantara permukaan kontak benda yang bergesekan dan dapat mengakibatkan kegagalan material sebagai kegagalan aus abrasive. Kondisi ini dapat mengakibatkan tingkat keausan material pada suhu permukaan dari $50{ }^{\circ} \mathrm{C}$ sampai dengan 
$250{ }^{\circ} \mathrm{C}$ menjadi lebih besar dibandingkan dengan tingkat keausan yang terjadi pada material pada suhu permukaan $30^{\circ} \mathrm{C}$.

Gambar 4a sampai dengan 4f menunjukkan permukaan aus material baja karbon sedang dengan variasi suhu permukaan 30, 50,100, 150, 200 dan $250{ }^{\circ} \mathrm{C}$ dengan beban normal sebesar $25 \mathrm{~N}$ melalui bola indentor, kecepatan sliding sekitar $0.1 \mathrm{~m} / \mathrm{s}$ dan dengan jarak sliding $100 \mathrm{~m}$. Dari keseluruhan gambar permukaan aus terlihat goresan yang terjadi sangat dangkal dan tipis. Ini menunjukkan permukaan material baja karbon tergerus sangat sedikit disetiap pembebanan yang besarnya antara $0,0173 \times 10^{-3}$ dan $0,0255 \times 10^{-3} \mathrm{gr} / \mathrm{m}$. Hal ini mungkin akibat dari adanya lapisan oksida di permukaan yang memperkecil gesekan dan membatasi terjadinya kontak langsung antara material sepesimen uji dan bola indentor. Kombinasi beban normal dan beban geser mengakibatkan material di permukaan mengalami deformasi plastis sesuai arah beban geser, sehingga terlihat seperti flak panjang. Material dipermukaan yang tergerus bola indentor sebagian terlepas sebagai partikel aus, sebagian terdeformasi dan terakumulasi melekat di ujung. Hal ini terjadi karena material baja karbon sedang tergolong material yang ulet dan dapat menjadi lebih ulet jika suhu dipermukaan mampu menurunkan sifat mekanis material. Hal ini juga menunjukkan jika tingkat keausan material pada suhu permukaan $100{ }^{\circ} \mathrm{C}$ sampai dengan $250^{\circ} \mathrm{C}$ lebih kecil dibandingkan dengan tingkat keausan yang terjadi pada material dengan suhu permuaan $50{ }^{\circ} \mathrm{C}$. Dimana pada suhu permukaan $100{ }^{\circ} \mathrm{C}$ sampai dengan $250{ }^{\circ} \mathrm{C}$ permukaan aus terlihat tergerus lebih dalam dan lebar, akan tetapi ada sebagian material terdeformasi dan terakumulasi diujung permukaan aus dan belum terlepas sebagai partikel aus. Kondisi menunjukkan bahwan material baja karbon pada suhu permukaan $100{ }^{\circ} \mathrm{C}$ sampai dengan $250{ }^{\circ} \mathrm{C}$ lebih mudah terdeformasi dibandingkan pada suhu permukaan dibawah $100{ }^{\circ} \mathrm{C}$, hal ini karena kekuatan luluh material pada suhu diatas $100{ }^{\circ} \mathrm{C}$ mengalami penurunan. Permukaan aus pada suhu $250{ }^{\circ} \mathrm{C}$ juga terlihat lebih kasar dibandingkan dengan permukaan aus pada suhu $30^{\circ} \mathrm{C}$, hal ini mungkin karena kekerasan material pada suhu $250{ }^{\circ} \mathrm{C}$ lebih kecil dibandingkan dengan suhu $30^{\circ} \mathrm{C}$. Jika permukaan material memiliki kekerasan lebih tinggi mengalami goresan, goresannya cenderung akan lebih halus dibandingkan dengan material yang lebih lunak [15].

Gambar 5 menunjukkan komposisi kimia pada permukaan aus baja karbon sedang dengan suhu permukaan $50{ }^{\circ} \mathrm{C}$. Dari gambar terlihat adanya dua unsur penting dalam proses oksidasi, yaitu unusur Fe dan O yang jumlahnya pada permukaan aus berturut-turut besarannya 63,15 dan 31,03\%. Lapisan oksida yang terbentuk kemungkinan adalah $\mathrm{Fe}_{3} \mathrm{O}_{4}$ disebabkan suhu permukaan material saat proses uji aus masih diantara 50 dan $260{ }^{\circ} \mathrm{C}$ [9]. Untuk memahami lebih jelas bagaimana pengaruh lapisan oksida terhadap tingkat dan mekanisme aus yag terjadi, perlu dilakukan pengamatan lebih mendalam terhadap seberapa besar laju pembentukan lapisan oksida terhadap suhu permukaan, sehingga diperoleh gambaran ketebalan lapisan oksida. Ketebalan lapisan oksida tentunya akan mempengaruhi waktu yang diperlukan untuk mendegradasi lapisan oksida dari permukaan material sebelum kontak langsung terjadi antara material yang mengalami gesekan. Demikian juga dengan perubahan beban gesekan yang terjadi dengan terbentuknya lapisan oksida dan juga laju degradasi lapisan oksida terhadap beban gesek yang diberikan.

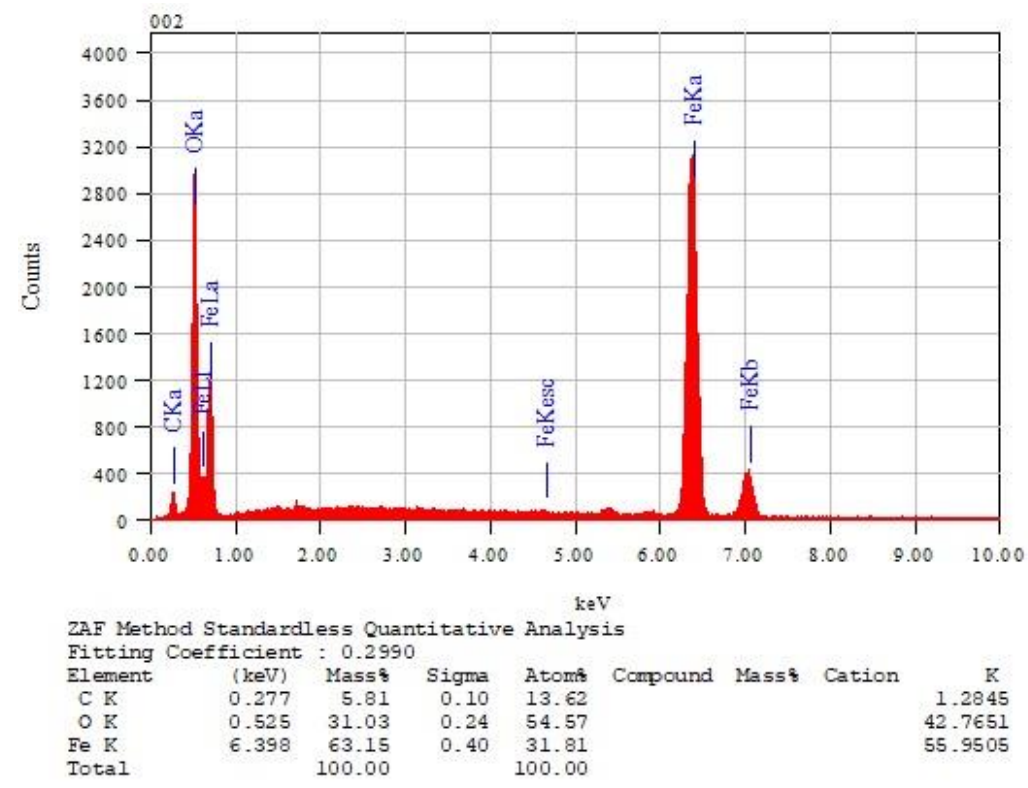

Gambar 5. Hasil EDS permukaan aus baja karbon sedang pada suhu $50^{\circ} \mathrm{C}$ 


\section{KESIMPULAN}

Meningkatnya suhu permukaan material baja karbon sedang dari $30^{\circ} \mathrm{C}$ menjadi $50{ }^{\circ} \mathrm{C}$ sampai dengan $250{ }^{\circ} \mathrm{C}$ mengakibatan terbentuknya lapisan oksida di permukaan material. Lapisan oksida memberikan kontribusi yang cukup besar dalam proses terjadinya keausan pada material baja karbon sedang. Lapisan oksida dapat berfungsi sebagai lapisan pelindung permukaan baja karbon sedang dari kontak langsung dengan material bola indentor, sehingga memperlambat terjadinya kegagalan aus material. Kondisi ini mengakibatkan tingkat keausan yang terjadi mengalami kenaikan cukup kecil yaitu antara $0,0173 \times 10^{-3}$ dan $0,0255 \times 10^{-3} \mathrm{gr} / \mathrm{m}$. Pada suhu permukaan diatas $100{ }^{\circ} \mathrm{C}$, material pada permukaan aus mengalami deformasi lebih besar, hal ini menunjukkan suhu permukaan dari $100{ }^{\circ} \mathrm{C}-250{ }^{\circ} \mathrm{C}$ mampu menurunkan kekuatan luluh materil. Mekanisme aus yang terjadi dengan kenaikan suhu permukaan sampai $250{ }^{\circ} \mathrm{C}$ tersebut dapat diidentifikasi dan dikategorikan sebagai bentuk keausan oksida.

\section{DAFTAR PUSTAKA}

[1] A. KAPOOR and F. J. FRANKLIN, "Tribological layers and the wear of ductile materials," Wear, vol. 245, no. 1-2, pp. 204-215, 2000.

[2] F. J. FRANKLIN, I. WIDIYARTA, and A. KAPOOR, "Computer simulation of wear and rolling contact fatigue," Wear, vol. 250, no. 251, pp. 949-955, 2001.

[3] Y. C. LIN, S. W. WANG, and T. M. CHEN, "A study on the wear behavior of hardened medium carbon steel," J. Mater. Process. Technol., vol. 120, no. 1-3, pp. 126-132, 2002.

[4] JEAN-MARC FRANSSEN and PAULO VILA REAL, Fire Design of Steel Structures, 2nd ed. ECCS - European Convention for Constructional Steelwork, 2015.

[5] D. PAYANA, I. M. WIDIYARTA, and M. SUCIPTA, "Kekerasan Baja Karbon Sedang dengan Variasi Suhu Permukaan Material," J. METTEK, vol. 4, no. 2, p. 43, 2018.

[6] I. M. WIDIYARTA, F. J. FRANKLIN, and A. KAPOOR, "Modelling thermal effects in ratchetingled wear and rolling contact fatigue," Wear, vol. 265, no. 9-10, pp. 1325-1331, 2008.

[7] T. GU, D. TANG, Z. WANG, H. CHEN, and H. XIE, "Effect of typical ions on the corrosion behavior of carbon steel in CO2 environment," Nat. Gas Ind., vol. 39, no. 7, pp. 106-112, 2019.

[8] T. TANUPABRUNGSUN, B. BROWN, and S. NESIC, "Effect of pH on CO2 corrosion of mild steel at elevated temperatures," NACE - Int. Corros. Conf. Ser., no. 2348, pp. 1-11, 2013.

[9] G. A. HENSHALL, "Numerical predictions of dry oxidation of iron and low-carbon steel at moderately elevated temperatures," Mater. Res. Soc. Symp. - Proc., vol. 465, no. November, 1997.

[10] N. BETRAND, C. DESGRANGES, D. POQUILLON, M. C. LAFONT, and D. MONCEAU, "Iron oxidation at low temperature $\left(260-500{ }^{\circ} \mathrm{c}\right)$ in air and the effect of water vapor," Oxid. Met., vol. 73 , no. $1-2$, pp. 139-162, 2010.

[11] AADARSH MISHRA, "Oxidation wear mechanism of cast steels," Int. J. Mech. Eng. Rob. Res., vol. 3, no. 3, pp. 588-592, 2014.

[12] I. KOVARIKOVA, B. SZEWCZYKOVA, P. BLAKOVITS, E. HODULOVA, and E. LECHOVIC, "Study and Characteristic of Abrasive Wear Mechanisms," Mater Sci Technol,1:1335-9053, pp. 1-9, 2015.

[13] "Standard Test Method for Linearly Reciprocating Ball-on-Flat Sliding Wear," in ASTM Standard, ASTM International.

[14] I. M. WIDIYARTA, I. M. PARWATA, I. P. LLOKANTARA, and DWIPAYANA, "Effect of contact surface temperature on wear of nickel-chromium layer," AIP Conf. Proc., vol. 2187, no. December, 2019

[15] NUR MOHAMMAD ARIFIN, ACHMAD AS'AD SONIEF, WINARNO YAHDI ATMOJO, "Pengaruh Parameter Proses Freis Terhadap Kekasaran Permukaan Baja Karbon Fasa Ganda," Jurnal Rekayasa Mesin, vol. 2, No. 3, pp. 182-192, 2011. 